\title{
The effect of education on decreasing the prevalence and severity of neck and shoulder pain: a longitudinal study in Korean male adolescents
}

\author{
Min Jung Koh ${ }^{1}$, Sun Young Park ${ }^{2}$, Eun Jung Park ${ }^{3}$, Sang Hoon Park ${ }^{2}$, Hea Rim Jeon ${ }^{2}$, Mun-Gyu Kim²,
} Se-Jin Lee ${ }^{2}$, Sang Ho Kim², Si Young $\mathrm{Ok}^{2}$, and Soon $\mathrm{Im} \mathrm{Kim}^{2}$

${ }^{1}$ St. Mark's School, Massachustts, USA, ${ }^{2}$ Department of Anesthesiology and Pain Medicine, Soonchunhyang University Seoul Hospital, ${ }^{3}$ Department of Pain Medicine, Godoil Hospital, Seoul, Korea

Background: Neck and shoulder pain is fairly common among adolescents in Korea and results in significant health problem. The aims of this prospective study was to identify the effects of education, in terms of recognition of this issue and posture correction, on prevalence and severity of neck and shoulder pain in Korean adolescents.

Methods: A prospective, observational cohort design was used. The 912 students from two academic high schools in the city of Seoul were eligible for the current study and 887 completed this study. After a baseline cross-sectional survey, students listened to a lecture about cervical health, focusing on good posture, habits, and stretching exercises to protect the spine, and were encouraged by their teachers to keep the appropriate position. And follow-ups were conducted 3 months later, to evaluate the effect of education.

Results: The prevalence of neck and shoulder pain was decreased 19.5\% (from 82.5 to $66.4 \%$ ). The baseline mean usual and worst numeric rating scale were 19.9/100 (95\% CI, 18.1-21.7) and 31.2/100 (95\% CI, 28.7-33.2), respectively. On the follow-up survey, the mean usual and worst numeric rating scale were decreased significantly by 24.1 and $21.7 \%$, respectively, compared with baseline $(\mathrm{P}<0.01)$. Of the 570 students reporting neck and shoulder pain, $16.4 \%$ responded that they had experienced improvement during the 3 months.

Conclusions: Education; recognition of this issue and posture correction, for cervical health appeared to be effective in decreasing the prevalence and severity of neck and shoulder pain at a 3 month follow-up. (Korean J Anesthesiol 2014; 67: 198-204)

Key Words: Education, Neck pain, Shoulder pain, Prevalence, Students.

Received: September 26, 2013. Revised: 1st, March 28, 2014; 2nd, April 21, 2014. Accepted: May 7, 2014.

Corresponding author: Sun Young Park, M.D., Department of Anesthesiology and Pain Medicine, Soonchunhyang University Seoul Hospital, 59, Daesagwan-ro, Yongsan-gu, Seoul 140-743, Korea. Tel: 82-2-709-9291, Fax: 82-2-790-0394, E-mail: sunnypark97@gmail.com

(c) This is an open-access article distributed under the terms of the Creative Commons Attribution Non-Commercial License (http:// creativecommons.org/licenses/by-nc/3.0/), which permits unrestricted non-commercial use, distribution, and reproduction in any medium, provided the original work is properly cited. 


\section{Introduction}

Neck and shoulder pain (NSP) is a relatively mild musculoskeletal condition, but is common enough to be a public health problem [1-4]. Not only are the neck and upper limb the most common sites of pain in adolescents, but also substantial number of adolescents complain of NSP [5,6]. A longitudinal study has suggested that NSP generated during adolescence was associated with a high prevalence of NSP during adulthood [7]. NSP results in significant disability in the general population $[1,8]$ and has an economic impact [9]. Thus, this issue of NSP in adolescents should not be disregarded, and the recognition and management of NSP in adolescents may be important for preventing NSP in adulthood.

In previous studies, the prevalence of recurrent NSP in Korean high school students was higher than $30 \%$, and the overall prevalence of NSP was almost $80 \%[10,11]$. It was more common than in Europe $[7,12,13]$. Korean adolescents spend a significant amount of time sitting, and considerable number of students sits in inappropriate posture [10]. Presumably, remaining in an unsuitable static position for a prolonged period of time results in minor injuries to muscles and ligaments that possibly cause the high prevalence of NSP in Korean adolescents. We suspect that proper education and lifestyle modification for Korean adolescents may decrease the prevalence or severity of NSP.

Although several studies have focused on the etiology of NSP during adolescence, few studies have addressed the management or prevention of NSP in adolescents, despite its high prevalence in this age group. The aim of this prospective study was to identify the effects of education, in terms of recognition of this issue and posture correction, on prevalence and severity of NSP in Korean adolescents.

\section{Materials and Methods}

The Institutional Review Board approved the present study protocol and the study was registered with Clinical Trials.gov. In 2012, a total of 1,302 male students from academic high schools in the city of Seoul were eligible for the current study, and after getting informed consent from the students and their teachers, 912 students ranging in age from 16 to 19 years participated (Fig. 1). The students completed a questionnaire in class in the presence of a teacher. The study design consisted of three phases: (i) a baseline cross-sectional survey, (ii) an education and posture correction and (iii) a follow-up survey of the baseline responders 3 months.

\section{Baseline survey}

The baseline survey consisted of a questionnaire, delivered to students at the school, which included site-specific questions regarding pain in different areas of the body: head, neck and shoulder, elbow, wrist, back, groin, knee, and foot. The students were asked whether they had experienced NSP during the previous 1 month period and were requested to classify this NSP according to six frequency and intensity levels. Multiple openchoice questions inquired about the times when NSP usually occurred, the activities that induced NSP, and any subjective NSP-induced difficulties in daily living. To assess the severity of NSP, the students were asked to use a numeric rating scale (NRS; range, $0-100$; no pain 0 to worst pain imaginable 100) to score the usual and worst NSP symptoms experienced during the preceding 1-week period. To evaluate disability, the Korean version of the Neck Disability Index (NDI) was used [14]. Total NDI scores were interpreted as follows: $0-4$, no disability; $5-14$, mild disability; 15-24, moderate disability; 25-34, severe disability; $>34$, complete disability. Students also completed the validated Korean version of the Short Form-36 (SF-36) questionnaire [15], which measures self-reported health and quality of life.

The questionnaire included potential associated factors also. An accident history was questioned. As an overall measure of self-reported health on a five-point scale, the students were asked 'would you say that, compared with others of the same age, your health is generally: excellent, good, fair, poor, or very poor?' Symptoms of fatigue were measured by symptom presence and frequency questions, with responses ranging from 1 to 5 ( 1 , never; 2 , seldom; 3 , sometimes; 4 , frequently; 5 , almost always). The degree of stress was examined using the validated

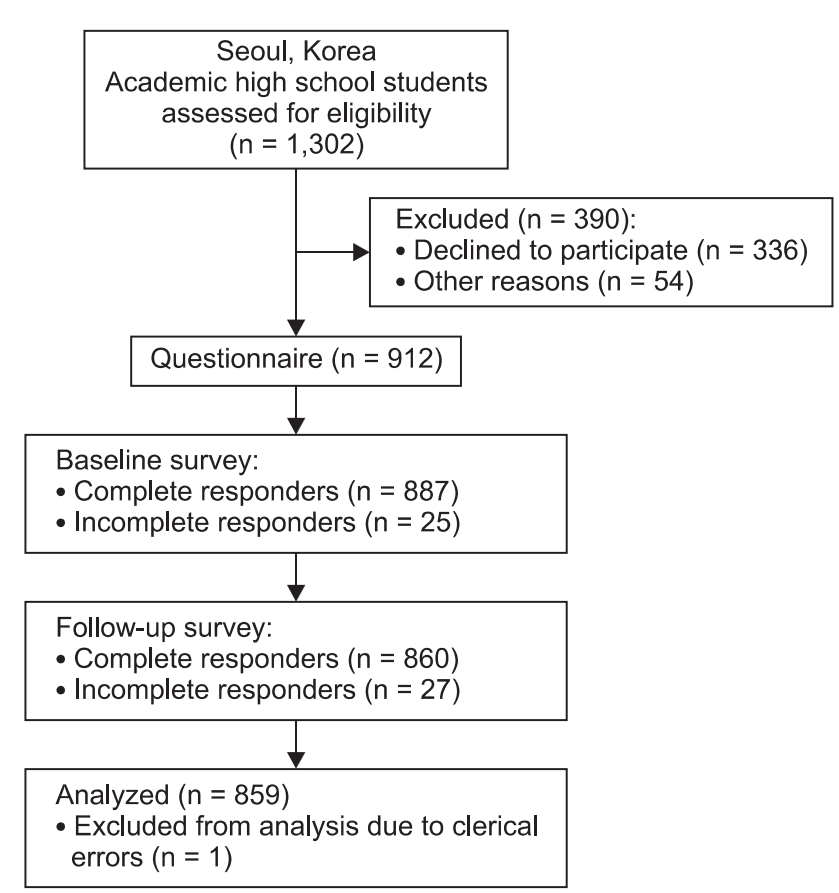

Fig. 1. Study design. 
Korean version of the Brief Encounter Psychosocial Instrument (BEPSI) [16], and the severity of depression was evaluated with the Beck Depression Inventory (BDI) [17].

To assess the activity and lifestyle of the students, we surveyed the daily duration of sitting during school and at home, sitting posture (e.g., slouching or lean back position, cross legs, forwardleaning head posture) during lessons, use of assisting devices for reading (e.g., a bookstand or armrest), and regularity of stretching. Sleep position, pillow type, average sleep duration, and sleep quality (1, excellent; 2 , good; 3 , fair; 4 , poor) were recorded. We asked whether the students had cervical problems, tried to maintain fine posture, or ever received education or posture correction for cervical health. Additionally, the students described any leisure activities and exercise, using a five-point scale to score the intensity of physical activity and the frequency of exercise (1, almost daily; 2 , frequently; 3 , sometimes; 4 , seldom; 5 , never).

\section{Education and posture correction}

After the baseline survey, the students and their teachers listened to a lecture concerning the fine posture for health [18]. The lesson included five parts with pictures and movies. Each session takes 15-20 minutes, and proceeded sequentially. Two clinicians, who have specialty on neurosurgery and pain management, presented the lesson. And the movies made by one professional instructor and a narrator under supervision by the clinicians. And fifteen staffs, who trained for this lecture, assisted and encouraged to follow the exercises, and answered the questions.

Part 1 taught the students and teachers how to maintain a healthy posture, emphasizing the detrimental effects of a sedentary lifestyle. Harmful positions, including sitting cross-legged on the floor and sitting with a rounded back, that could cause spine or muscular injury were listed. Students were cautioned to avoid crossing the legs and sitting on the edge of a chair. How to establish good posture when sitting on a chair was described: keep the spine straight; relax the shoulders, position forearms and hands in a straight line, and place feet flat on the floor. Also, the lower back should be supported, and the thighs should be in a horizontal position. A distance of 18-28 inches between a book or screen and the eyes was recommended.

In Part 2, the students and teachers learned about good posture and the importance of being aware of posture. Pictures of inappropriate standing positions and normal posture as well as pictures of the ideal sitting position and optimal spine curvature were presented. Information was provided regarding how many vertebrae comprise the human spine and the detrimental effects of bad posture and bad habits, such as forward head posture, on the spine.

Part 3 explained the impacts that sleep position can have on health, advising that a pillow should not be too high or too hard. Part 4 provided guidance regarding the use a cellular phone or computer, wearing a backpack, keeping the back straight by tucking in the chin, and using a bookstand while reading or studying.

In Part 5, the students and teachers were guided through the motions of exercises for stretching and strengthening the neck. They practiced the chin-tuck position, standing tall exercise, head half-roll and shoulder roll exercises, side neck bend, neck flexion and extension, and exercises to strengthen neck muscles. Afterward, the teachers continued to encourage the students to maintain an appropriate position and made efforts to correct their posture.

\section{Follow-up survey}

Follow-ups were conducted 3 months later, in the same way as the baseline survey. To evaluate the effect of education, students were asked to score the usual and worst NSP symptoms experienced during the preceding 1-week period, using the NRS (range, 0-100). The Korean version of the NDI was also examined. The self-reported change in NSP was classified according to three categories (decreased, unchanged, and increased).

\section{Statistical methods}

The primary outcome variable was the NRS score of NSP during the 1-week period preceding follow-up. Secondary outcomes were prevalence of NSP, NDI scores, activity and lifestyle, associated factors for NSP, and results of the SF-36 questionnaire.

The variables are shown as percentages with $95 \%$ confidence intervals $(\mathrm{CI})$, means \pm standard deviation (SD), or absolute values. Differences in the NRS scores were analyzed using a paired t-test. The associations between NSP and other variables were analyzed with a chi-squared test or Student's t-test. Linear trends across categories were determined using a linear-by-linear association for ordinal variables. The adjusted odds ratio and 95\% CI of the potential associated factors for predicting the likelihood of NSP (number of other pains, accident history, self-reported health, fatigue, NDI, BEPSI, BDI, sleep quality, sitting position, use of assisting devices) were analyzed using logistic regression analysis. The influence of NSP on quality of life, as measured by the SF-36, was assessed using Student's t-test. The reliability of the present survey estimated based on internal consistency reached a Cronbach's alpha of 0.7. Statistical analyses were performed using SPSS 12.0 (SPSS, Inc., Chicago, IL, USA). Values of $\mathrm{P}<0.05$ (two-tailed) were deemed to indicate statistical significance. 


\section{Results}

The study design is outlined in Fig. 1. Among the 912 students who participated, 887 completed the baseline question-

Table 1. Characteristics of Neck and Shoulder Pain in the Previous 1-month Period

\begin{tabular}{|c|c|c|}
\hline Characteristic & Number & $\begin{array}{c}\text { Percentage } \\
(95 \% \mathrm{CI})\end{array}$ \\
\hline \multicolumn{3}{|l|}{ Frequency $(\mathrm{n}=859)$} \\
\hline Never & 150 & $17.4(15.0-19.9)$ \\
\hline Once a month & 296 & $34.5(31.3-37.5)$ \\
\hline Once every $2-3$ weeks & 154 & $17.9(15.5-20.4)$ \\
\hline Once a week & 102 & $11.9(9.8-14.2)$ \\
\hline Once every $2-3$ days & 86 & $10.0(7.9-12.0)$ \\
\hline Almost daily & 71 & $8.3(6.5-10.4)$ \\
\hline \multicolumn{3}{|l|}{ Intensity at this point $(\mathrm{n}=858)$} \\
\hline None & 149 & $17.4(14.8-19.9)$ \\
\hline Slight & 432 & $50.3(47.1-53.8)$ \\
\hline Mild & 211 & $24.6(21.7-27.5)$ \\
\hline Moderate & 55 & $6.4(4.8-8.20)$ \\
\hline Severe & 10 & $1.2(0.5-1.9)$ \\
\hline Extreme & 1 & $0.1(0.0-0.3)$ \\
\hline \multicolumn{3}{|c|}{ Activity that induced NSP $(\mathrm{n}=840)$} \\
\hline Lessons & 290 & $34.5(31.1-37.7)$ \\
\hline Computer use & 261 & $31.3(28.0-34.4)$ \\
\hline Homework & 187 & $22.3(19.6-25.2)$ \\
\hline Exercise & 148 & $17.6(15.0-20.2)$ \\
\hline Cellular phone use & 133 & $15.8(13.6-18.2)$ \\
\hline \multicolumn{3}{|c|}{ Subjective NSP-induced difficulty $(\mathrm{n}=790)$} \\
\hline In studying & 205 & $25.9(23.0-28.9)$ \\
\hline In physical activities & 176 & $22.3(19.4-25.1)$ \\
\hline In sleep & 151 & $19.1(16.3-21.8)$ \\
\hline In usual activities & 116 & $14.7(12.4-17.1)$ \\
\hline In leisure activities & 72 & $9.1(7.1-11.0)$ \\
\hline In emotional stability & 50 & $6.3(4.7-8.0)$ \\
\hline
\end{tabular}

Data from baseline survey. Numbers do not always add to 859 because of missing data for some factors. NSP: neck and shoulder pain, CI: confidence interval. Multiple open-choice questions inquired about the activities that induced NSP, and any subjective NSP-induced difficulties in daily living. naire. Their mean age was $17.6 \pm 3.1$ years, mean weight was $66.4 \pm 11.4 \mathrm{~kg}$, and mean height was $174.3 \pm 5.5 \mathrm{~cm}$. The number of drop-outs on the follow-up survey was 27: 15 were missing data and 12 could not be identified because of clerical errors. The reliability of the present survey had a Cronbach's alpha of 0.883 , based on internal consistency.

Regarding the site-specific questionnaire; head 51.5\%, elbow $38.2 \%$, wrist $39.1 \%$, back $48.7 \%$, groin $33.4 \%$, knee $38.9 \%$, and foot $42.3 \%$ students experienced pain in each area. In the baseline survey, $82.5 \%$ (95\% CI, 71.0-86.1) of 859 students experienced NSP during the previous 1 month period. The pain characteristics are presented in Table 1 . The activities most commonly reported to induce NSP were lessons (34.5\%), computer use $(31.3 \%)$, and homework (22.3\%). In addition, 25.9\% experienced difficulty in studying because of their NSP. The mean usual and worst NRS scores of NSP during the 1-week period prior to the baseline survey were $19.9 / 100$ (95\% CI, 18.1-21.7) and 31.2/100 (95\% CI, 28.7-33.2), respectively. The mean NDI total score was 8.6 (95\% CI, 8.2-8.9), and $65.2 \%$ of the students showed mild disability. Except for the emotional components, all items in the SF-36 were affected by the presence of NSP (Table 2).

An accident history was reported by $8.3 \%$ of the students. We analyzed the adjusted odds ratio and 95\% CI for variable factors known to be potential associated factors for NSP (Table 3). Although the number of other musculoskeletal pains was a significant risk factor, it did not exhibit a linear trend $(\mathrm{P}=0.06)$. The NDI scores differed significantly according to NSP $(\mathrm{P}<0.01)$, whereas the BEPSI $(\mathrm{P}=0.951)$ and BDI $(\mathrm{P}=0.075)$ scores did not.

The average time that the students spent sitting was 11.5 (2.7) $\mathrm{h} /$ day, with $62.6 \%$ (95\% CI, 59.1-65.9) responding that they did not sit straight, and 52.2\% (95\% CI, 49.1-55.5) responding that they usually maintained a forward-leaning head posture. Only $10.3 \%$ (95\% CI, 8.3-12.4) used assisting devices while reading, and only $12.6 \%(95 \% \mathrm{CI}, 10.3-15.3)$ responded that they

Table 2. Health-related Quality of Life, as Measured by the Short Form-36, for Students Reporting Versus not Reporting Neck and Shoulder Pain

\begin{tabular}{|c|c|c|c|c|}
\hline SF-36 parameter & No NSP & NSP & Difference $(95 \% \mathrm{CI})$ & $P$ value \\
\hline Physical functioning & $89.4 \pm 1.3$ & $82.7 \pm 0.8$ & $6.7(2.8-10.5)$ & 0.001 \\
\hline Role physical & $78.8 \pm 1.6$ & $71.3 \pm 1.0$ & $7.4(2.7-12.2)$ & 0.002 \\
\hline Body pain & $88.8 \pm 1.1$ & $77.1 \pm 0.6$ & $11.7(8.7-14.7)$ & 0.000 \\
\hline General health & $69.8 \pm 1.3$ & $60.1 \pm 0.6$ & $9.7(6.6-12.8)$ & 0.000 \\
\hline Vitality & $60.9 \pm 1.3$ & $53.3 \pm 0.5$ & $7.5(4.9-10.1)$ & 0.000 \\
\hline Social functioning & $83.3 \pm 1.7$ & $74.8 \pm 0.8$ & $8.6(4.7-12.3)$ & 0.000 \\
\hline Role emotional & $74.7 \pm 1.8$ & $71.2 \pm 1.1$ & $3.4(-1.4-8.3)$ & 0.171 \\
\hline Mental health & $64.6 \pm 1.2$ & $57.8 \pm 0.6$ & $6.8(3.9-9.7)$ & 0.000 \\
\hline Physical component score & $78.2 \pm 1.1$ & $69.2 \pm 0.5$ & $8.9(6.7-11.2)$ & 0.000 \\
\hline Mental component score & $70.7 \pm 0.9$ & $63.5 \pm 0.5$ & $7.1(4.9-9.4)$ & 0.000 \\
\hline SF36 total score & $76.7 \pm 0.9$ & $68.8 \pm 0.5$ & $7.9(5.7-10.1)$ & 0.000 \\
\hline
\end{tabular}

Data from baseline survey. NSP: neck and shoulder pain, CI: confidence interval, SF-36, short form-36 questionnaire. The data are means \pm standard deviation (SD). 
stretched regularly. The prone position during sleep was preferred by $9.4 \%$ of students, and $17.5 \%$ used a relatively low pillow. The average sleep duration was $6.2 \pm 0.1 \mathrm{~h} /$ day, and $91.5 \%$ responded that their sleep quality was not bad. Cervical problems were reported as a concern in $64.3 \%$ (95\% CI, 61.0-67.2) of the students. However, $69.1 \%$ (95\% CI, 65.8-72.0) did not try to maintain fine posture, and $69.4 \%$ (95\% CI, 66.4-72.8) never received education or posture correction for cervical health. Among the $45.6 \%$ of the students who exercised frequently, $82.5 \%$ exercised until they experienced panting and sweating.

Of the 859 respondents to the follow-up survey, NSP dur-

Table 3. Potential Associated factors for Neck and Shoulder Pain

\begin{tabular}{|c|c|c|c|}
\hline Factor & Category & $\begin{array}{c}\text { Adjusted OR } \\
(95 \% \mathrm{CI})\end{array}$ & $P$ value \\
\hline Number of other pains* & $0-9$ & 1.175 & 0.009 \\
\hline \multirow[t]{2}{*}{ Accident history } & Yes & 1 & 0.821 \\
\hline & No & $0.50(0.20-1.25)$ & 0.139 \\
\hline \multirow[t]{5}{*}{ Health } & Excellent & 1 & 0.458 \\
\hline & Good & $1.66(0.85-3.24)$ & 0.136 \\
\hline & Fair & $1.41(068-2.89)$ & 0.351 \\
\hline & Poor & $2.89(0.76-10.9)$ & 0.117 \\
\hline & Very poor & $0.46(0.13-18.7)$ & 0.829 \\
\hline \multirow[t]{5}{*}{ Fatigue } & Never & 1 & 0.155 \\
\hline & Seldom & $2.25(0.79-6.41)$ & 0.127 \\
\hline & Sometimes & $2.90(0.97-8.68)$ & 0.056 \\
\hline & Frequently & $3.42(1.15-10.1)$ & 0.027 \\
\hline & Almost always & $1.23(0.24-6.22)$ & 0.796 \\
\hline NDI* & & $1.65(1.48-1.81)$ & 0.000 \\
\hline BEPSI & & $1.00(0.91-1.10)$ & 0.951 \\
\hline BDI & & $0.95(0.91-1.00)$ & 0.075 \\
\hline \multirow[t]{5}{*}{ Sleep quality } & Excellent & 1 & 0.506 \\
\hline & Good & $0.69(0.32-1.48)$ & 0.346 \\
\hline & Fair & $0.53(0.23-1.23)$ & 0.143 \\
\hline & Poor & $0.73(0.17-3.09)$ & 0.675 \\
\hline & Very poor & $3.36(0.14-7.57)$ & 0.445 \\
\hline \multirow[t]{2}{*}{ Sitting position* } & Good & 1 & 0.002 \\
\hline & Poor & $1.37(0.98-1.90)$ & 0.059 \\
\hline \multirow[t]{2}{*}{ Assisting device } & Yes & 1 & 0.531 \\
\hline & No & $0.84(0.52-1.35)$ & 0.485 \\
\hline
\end{tabular}

Data from baseline survey. NDI: Neck Disability Index, BEPSI: Brief Encounter Psychosocial Instrument, BDI: Beck Depression Inventory, OR: odds ratio, CI: confidence interval. *Indicates a significant difference $(\mathrm{P}<0.05)$ according to neck and shoulder pain. ing the previous 1 month period was reported by $66.4 \%(95 \%$ CI, 63.0-69.7), representing a significant decrease of $19.5 \%$ compared with baseline $(\mathrm{P}<0.01)$. On the follow-up survey, the mean usual and worst NRS scores of NSP during the prior 1-week period were 15.1/100 (95\% CI, 13.4-16.8) and 24.4/100 (95\% CI, 22.3-26.6), respectively. The mean usual and worst NRS of NSP was significantly decreased by $24.1 \%$ and $21.7 \%$, respectively, compared with baseline $(\mathrm{P}<0.01$; Fig. 2 ). Of the 570 students reporting NSP, $16.4 \%$ responded that they had experienced improvement during the 3 months preceding the followup survey. The mean NDI total score was 7.0 (95\% CI, 6.6-7.3), which differed significantly from the baseline score $(\mathrm{P}<0.01)$. Mild disability was present in $58.6 \%(55.4-61.8)$ of the students (Table 4).

\section{Discussion}

The high prevalence of NSP and significant disability and discomfort induced by it, emphasize the necessity of the effort for recognition and management of NSP in Korean adolescents. In the present study, we investigated the effects of education on the prevalence and severity of NSP. Although NSP affected the

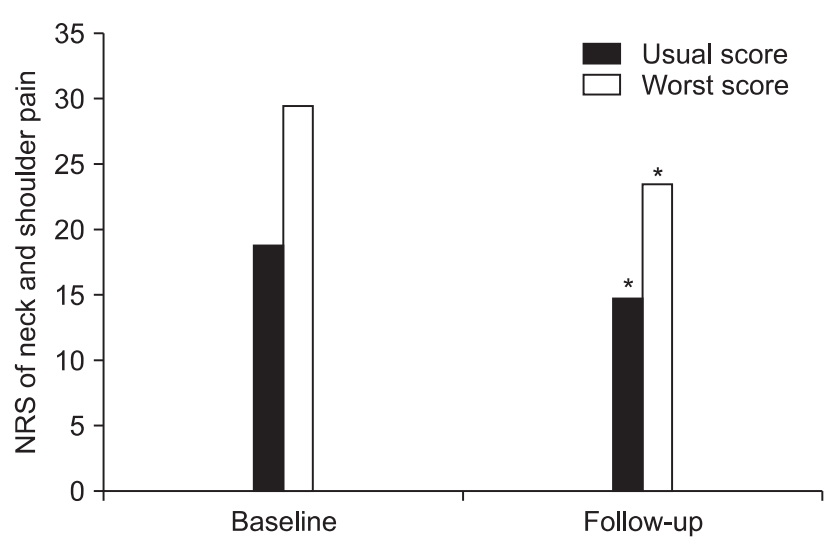

Fig. 2. The mean NRS of neck and shoulder pain at baseline and followup survey. The mean usual and worst NRS of NSP was significantly decreased by $24.1 \%$ and $21.7 \%$, respectively, compared with baseline $(* \mathrm{P}<0.01)$.

Table 4. Neck Disability Based on Total Neck Disability Index (NDI) Scores $(\mathrm{n}=857)$

\begin{tabular}{lccrc}
\hline NDI category & At baseline, number & $\begin{array}{c}\text { Percentage } \\
(95 \% \mathrm{CI})\end{array}$ & At follow-up, number & $\begin{array}{c}\text { Percentage } \\
(95 \% \mathrm{CI})\end{array}$ \\
\hline No disability & 195 & $22.9(20.0-25.7)$ & 294 & $34.3(31.0-37.7)$ \\
Mild & 560 & $65.2(62.6-68.6)$ & 502 & $58.6(55.4-61.8)$ \\
Moderate & 95 & $11.1(8.8-13.0)$ & 54 & $6.3(4.8-7.9)$ \\
Severe & 5 & $0.6(0.1-1.2)$ & 6 & $0.7(0.2-1.3)$ \\
Complete & 2 & $0.2(0.0-0.6)$ & 1 & $0.1(0.0-0.4)$ \\
\hline
\end{tabular}

Total scores of NDI are interpreted as follows: 0-4, no disability; 5-14, mild disability; 15-24, moderate disability; 25-34, severe disability; > 34, complete disability. CI: confidence interval. 
self-reported health and quality of life for many students in this study, most did not try to maintain optimal posture for health and never had received education to promote a cervical health. We lectured the students and subsequently encouraged to maintain an appropriate posture. After 3 months, the prevalence of NSP was decreased and the symptoms were significantly improved. Additionally, NDI scores that indicate disability were significantly decreased. This result could demonstrate not only the efficacy of education about the NSP and but also the importance.

In a study by Jung et al. [11], the prevalence of NSP in Korean high school students was $82.9 \%$, with $33.4 \%$ experiencing NSP weekly. In previous study [10], the overall prevalence of NSP in students was $79.1 \%$, and $44.3 \%$ had recurrent NSP, which are similar to the rates in Jung et al. [11] and confirm that NSP is more prevalent among Korean high school students compared with European students $[7,12,13]$. By contrast, adult studies have suggested a lower prevalence in Asian populations $[4,19]$. We suspect that the cause of the relatively high prevalence of NSP in Korean high school students is their lifestyle. Common causes of NSP include cervical strains and sprains, which can result from poor posture, poor sleep habits, chronic muscle fatigue, and trauma [20]. Korean high school students spend considerable time in a sitting position while doing schoolwork. In the present survey, the average time was $11.5 \mathrm{~h} /$ day, and many students responded that they usually maintained poor ergonomic positions. Additionally, only some used an assisting device while reading and few stretched regularly. Although some contradictory reports exist, repetitive and prolonged static postures have been found to initiate or exacerbate NSP [21-23]. Therefore we hypothesized that maintaining a forward-leaning head posture and static muscular activation patterns for prolonged periods while studying can partially explain the high prevalence of NSP in students, and that education and position modification may be helpful in improving symptoms in these students. Consequentially, we found beneficial effects; 3 months after the students listened to a lecture about cervical health, focusing on good posture, habits, and stretching exercises, and were encouraged by their teachers to keep the appropriate position. This result supports our hypothesis and confirms the importance of the education.
Psychosocial factors are considered to be important risk factors for NSP. Siivola et al. [7] showed that psychosomatic symptoms, fatigue, and sleep difficulties were associated with a higher prevalence of NSP. Additionally, self-assessed poor health and psychological distress were reported associating with increased incidence of neck pain [19]. In cross-sectional studies, depressive symptoms $[24,25]$ have also been linked to NSP in adolescents. Based on those results, NSP could be a psychosomatic symptom. However, we should not focus only on these psychological factors nor underestimate nociceptive and musculoskeletal mechanical factors in NSP. In this study, self-reported health, symptoms of fatigue, BEPSI and BDI scores did not differed significantly according to NSP. Croft et al. [19] also suggested that, in those who have had a neck injury, the injury itself is probably the biggest single influence on the development of recurrent neck pain. Additionally, Paananen et al. [26] presented that both psychosocial and lifestyle factors contribute to high persistent tendency of musculoskeletal pains in adolescence. We speculate that NSP reflects the nature and site of an injury, even a minor injury, according the lifestyle in high school students. Thus, we need to make an effort to prevent the injury by correcting poor posture. Education on this issue is part of the effort and this report could be an evidence of the effect of it.

The present study has several limitations. First, as the followup time was fairly short to exclude the influence of the classroom activities (e.g. final exam) on the outcome, we cannot confirm long-term effects of education. Second, we could not determine the exact reasons for NSP in the students, and therefore the impact of education on NSP is speculative. Third, because the data were self-reported, we could not exclude recall bias. Additionally, because the small sample size, the current study is unlikely to represent all Korean high school students. Furthermore, all of the participants were male, although symptoms have been found more frequently among female than male adolescents [19,27].

In conclusion, Korean high school male students had a high prevalence of NSP. Education; recognition of this issue and posture correction, for cervical health appeared to be effective in decreasing the prevalence and severity of NSP at a 3-monthfollow-up. Base on these results, we suggest educating adolescents about NSP and its prevention.

\section{References}

1. Côté P, Cassidy JD, Carroll L. The Saskatchewan Health and Back Pain Survey. The prevalence of neck pain and related disability in Saskatchewan adults. Spine (Phila Pa 1976) 1998; 23: 1689-98.

2. Guez M, Hildingsson C, Nilsson M, Toolanen G. The prevalence of neck pain: a population-based study from northern Sweden. Acta Orthop Scand 2002; 73: 455-9. 
3. Hogg-Johnson S, van der Velde G, Carroll LJ, Holm LW, Cassidy JD, Guzman J, et al. The burden and determinants of neck pain in the general population: results of the Bone and Joint Decade 2000-2010 Task Force on Neck Pain and Its Associated Disorders. Spine (Phila Pa 1976) 2008; 33(4 Suppl): S39-51.

4. Lau EM, Sham A, Wong KC. The prevalence of and risk factors for neck pain in Hong Kong Chinese. J Public Health Med 1996; 18: 396-9.

5. Hakala P, Rimpelä A, Salminen JJ, Virtanen SM, Rimpelä M. Neck, and shoulder pain in Finnish adolescents: national cross sectional surveys. BMJ 2002; 325: 743.

6. Ehrmann Feldman D, Shrier I, Rossignol M, Abenhaim L. Risk factors for the development of neck and upper limb pain in adolescents. Spine (Phila Pa 1976) 2002; 27: 523-8.

7. Siivola SM, Levoska S, Latvala K, Hoskio E, Vanharanta H, Keinänen-Kiukaanniemi S. Predictive factors for neck and shoulder pain: a longitudinal study in young adults. Spine (Phila Pa 1976) 2004; 29: 1662-9.

8. Picavet HS, Schouten JS. Musculoskeletal pain in the Netherlands: prevalences, consequences and risk groups, the DMC(3)-study. Pain 2003; 102: 167-78.

9. Meerding WJ, Bonneux L, Polder JJ, Koopmanschap MA, van der Maas PJ. Demographic and epidemiological determinants of healthcare costs in Netherlands: cost of illness study. BMJ 1998; 317: 111-5.

10. Koh MJ, Park SY, Woo YS, Kang SH, Park SH, Chun HJ, et al. Assessing the prevalence of recurrent neck and shoulder pain in Korean high school male students: A cross-sectional observational study. Korean J Pain 2012; 25: 161-7.

11. Jung HJ, Somg YM, Kim HY, Chung JI. Prevalence and associated factors of neck and shoulder pain in high school students. J Korean Acad Fam Med 2008; 29: 595-603.

12. Diepenmaat AC, van der Wal MF, de Vet HC, Hirasing RA. Neck/shoulder, low back, and arm pain in relation to computer use, physical activity, stress, and depression among Dutch adolescents. Pediatrics 2006; 117: 412-6.

13. van Gent C, Dols JJ, de Rover CM, Hira Sing RA, de Vet HC. The weight of schoolbags and the occurrence of neck, shoulder, and back pain in young adolescents. Spine (Phila Pa 1976) 2003; 28: 916-21.

14. Song KJ, Choi BW, Kim SJ, Yoon SJ. Cross-clutural adaptation and validation of the Korean version of the Nck Disability Index. J Korean Orthop Assoc 2009; 44: 350-9.

15. Kim SA, Park KS, Jang MK, Kam S. Medical facilities utilization according to health status measured by SF-36 in male workers. Korean J Occup Environ Med 2006; 18: 272-83.

16. Bae JM, Jeong EK, Yoo TW, Huh BY, Kim CH. A quick measurement of stress in outpatient clinic setting. J Korean Acad Fam Med 1992; 13: 809-20.

17. Park HJ, Kim HM, Kim IB, Jeon SA. Reliability of the Beck Depression Inventory in adolescence. J Korean Acad Fam Med 2000; $21: 244-53$.

18. Borenstein DG, Wiesel SW, Boden SD. Low back and neck pain: comprehensive diagnosis and management, 3rd ed. Philadelphia, WB Saunders. 2004, pp 793-9.

19. Croft PR, Lewis M, Papageorgiou AC, Thomas E, Jayson MI, Macfarlane GJ, et al. Risk factors for neck pain: a longitudinal study in the general population. Pain 2001; 93: 317-25.

20. Fishman SM, Ballantyne JC, Rathmell JP. Neck and arm pain, In: Bonica's management of pain. 4th ed. Philadelphia, Lppincott Williams \& Wilkins. 2010, pp 1030-4.

21. Barnekow-Bergkvist M, Hedberg GE, Janlert U, Jansson E. Determinants of self-reported neck-shoulder and low back symptoms in a general population. Spine (Phila Pa 1976) 1998; 23: 235-43.

22. Bergström G, Bodin L, Bertilsson H, Jensen IB. Risk factors for new episodes of sick leave due to neck or back pain in a working population. A prospective study with an 18-month and a three-year follow-up. Occup Environ Med 2007; 64: 279-87.

23. Fredriksson K, Alfredsson L, Köster M, Thorbjörnsson CB, Toomingas A, Torgén M, et al. Risk factors for neck and upper limb disorders: results from 24 years of follow up. Occup Environ Med 1999; 56: 59-66.

24. Niemi SM, Levoska S, Rekola KE, Keinänen-Kiukaanniemi SM. Neck and shoulder symptoms of high school students and associated psychosocial factors. J Adolesc Health 1997; 20: 238-42.

25. Härmä AM, Kaltiala-Heino R, Rimpelä M, Rantanen P. Are adolescents with frequent pain symptoms more depressed? Scand J Prim Health Care 2002: 20; 92-6.

26. Paananen MV, Taimela SP, Auvinen JP, Tammelin TH, Kantomaa MT, Ebeling HE, et al. Risk factors for persistence of multiple musculoskeletal pains in adolescence: a 2-year follow-up study. Eur J Pain 2010; 14: 1026-32.

27. Ståhl M, Mikkelsson M, Kautiainen H, Häkkinen A, Ylinen J, Salminen JJ. Neck pain in adolescence. A 4-year follow-up of pain-free preadolescents. Pain 2004; 110: 427-31. 